\title{
The improvement of thermal characteristics of autoclave aerated concrete for energy efficient high-rise buildings application
}

\author{
Pavel Khavanov ${ }^{1}$, Ekaterina Fomina ${ }^{2 *}$, and Natalia Kozhukhova ${ }^{2}$ \\ ${ }^{1}$ Moscow State University of Civil Engineering, Yaroslavskoe shosse, 26, Moscow, 129337, Russia \\ ${ }^{2}$ Belgorod State Technological University named after V.G. Shoukhov, 308012, Belgorod, Kostukova \\ Street, 46, Russia.
}

\begin{abstract}
Nowadays, the problem of energy saving is very relevant. One of the ways to reduction energy consumption in construction materials production and construction of civil and industrial high-rise buildings is the application of claddings with heat-insulating performance. The concept of energy efficiency of high-rise buildings is closely related to environmental aspect and sustainability of applied construction materials; reducing service costs; energy saving and microclimate comfortability. A complexity of architectural and structural design as well as aesthetic characteristics of construction materials are also should be considered. The high interest focused on materials with combined properties. This work is oriented on the study of energy efficiency of buildings by improving heat-insulation and strength performance of autoclave aerated concrete. The applied method of sulfate activation of lime allows monitoring phase and structure formation in aerated concrete. The optimal mix design of aerated concrete with the compressive strength up to $8.5 \mathrm{MPa}$ and decreased density up to $760 \mathrm{~kg} / \mathrm{m}^{3}$ was proposed. Analysis of structure at macro- and microscale was performed as well as the criteria of an optimal porosity formation was considered a number, size, shape of pore and density of interior partition. SEM analysis and BET method were performed in this research work. The research results demonstrated the correlation between structure and vapor permeability resistance, also it was found that the increase of strength can lead to reduction of thermal conductivity.
\end{abstract}

\section{Introduction}

The modern regulations require construction materials to meet the strict requirements for thermal and strength performance for construction of polyfunctional energy-saving high-rise buildings and residential complexes. Special requirement are made for materials applied in high-rise buildings. These materials should provide the required level of comfortability and optimal microclimate for human life and activities as well as required heat insulation [1]. Due to a significant environmental impact of construction materials production the energy

\footnotetext{
* Corresponding author: fomina.katerina@mail.ru
} 
efficiency of buildings become a problem number one in the construction sector [2]. A "Zeroenergy" house is one of the effective approaches in construction was introduced and become very popular in Europe [3].

The new generation composites are the functional materials with improved performance and combine several characteristics such as structural, decorative, thermal-insulation and sound insulation etc. [4]. The application of autoclave aerated concrete as building envelopes is a good way to realize the concept. Aerated concrete performs well in the constructions with steel reinforced-concrete and high-rise monolithic structures [5]. Nowadays, autoclave aerated concrete is a multi-purpose construction material, produced using «green» technology [6]. The aerated concrete is a light-weight structural material with high thermaland sound- insulation, reduced labor intensity; reduced transportation and others associated costs. Die to its light-weight and plasticity, aerated concrete can be easily cut in simple and more complex architectural elements, which allows to expand the applicability of the material and be a good fit in high-rise buildings and others complex structures construction where the use of high-density elements is not possible. Moreover, aerated concrete is characterized by low thermal-conductivity providing an optimal air condition control and microclimate.

Development of innovative approaches and energy-efficient and eco-friendly technologies for aerated concrete production with improved thermal characteristics is based on modification of cellular structure saving the strength performance [7-9]. Smart concrete is among of the innovative construction materials. It can work in extreme climate and service conditions [10] considering social and aesthetic aspects [11].

The reduction of density with saving and increasing of strength performance is the key factor for efficiency of production and application of aerated concrete. An effective method to achieve an excellent thermal-insulating characteristics in aerated concrete is the control of hydration process. Often, a low quality autoclave material is associated with uncompleted chemical interaction between lime and quartz components in the binder system. Therefore, intensity and completeness of lime slaking as well as chemical reactivity of $\mathrm{Ca}(\mathrm{OH})_{2}$ are the key parameters at first stage of hydration in order to produce a high quality material.

However, at industrial level of production, it is difficult to precisely control the hydration process. The previous studies [12] showed that slaking of high-reactive lime (reactivity is 86 $\%$, water demand is $32-64 \%$ ) at the temperature range of $160-190^{\circ} \mathrm{C}$ at the presence of $0.05-$ $0.25 \%$ gypsum, the gypsum dehydration takes place leading to formation of $\beta$-hemihydrate of calcium sulfate and $\mathrm{Ca}(\mathrm{OH})_{2}$-particles with higher dispersity. Incorporation of highdispersed $\mathrm{Ca}(\mathrm{OH})_{2}$ and $\beta$-hemihydrate calcium sulfate into the aerated concrete mixture causes the change in hydration kinetics, setting time and rheological performance [13-14]. In addition it helps to combine the periods of intensive structure formation and gas release (blow out of aerated concrete). That provides high-performance matrix structure of the final autoclave composite.

\section{Materials and Methods}

The mix of aerated concrete was designed to be applicable for a small-sized blocks cutting technology production in order to provide density of $800 \mathrm{~kg} / \mathrm{m}^{3}$ and compressive strength of 2.5-7.5 MPa [15]. The sulfate activation of lime was performed during binder specimens casting process. The $\beta$-hemihydrate calcium sulfate in content of $0.15 \%$ was added to lime. The obtained mixture was slaked. Water/ solid ratio was 0.32 . The obtained slaked binder was added into the aerated concrete mixture consisting of cement, aluminum paste and quartz sand. It was observed that the most intensive gas release was achieved with providing the certain thermal conditions during exothermic reaction caused by lime slaking process when. Therefore, only about $20 \%$ of the lime-gypsum mixture needs to be slaked before adding into the concrete mix. The mix of aerated concrete was poured in cubic metal 
forms of $10 \times 10 \times 10 \mathrm{~cm}$ using castable technology. The components of the aerated concrete mixture was in the following proportion: lime -1 ; quartz sand -3 ; cement -1 ; aluminum paste -0.0048 .

The poured specimens were cured in ambient conditions for 3 hours followed by autoclave treatment under the following curing regime: air-flush of the specimens in the curing chamber for $40 \mathrm{~min}$; after that pressure was buildup by up 10 atmospheres and temperature up to $180^{\circ} \mathrm{C}$ during 1 hour; curing process was performed at a constant 10 atmospheres and $180^{\circ} \mathrm{C}$ for 5 hours followed by pressure release during 2 hours. The portion of $\beta$-hemihydrate calcium sulfate in the binder was determined using cation-exchange method [16]. Microstructure of the aerated concrete was investigated using high-resolution scanning-electron microscope Hitachi S-800 and the microporosity of concrete specimens was measured by BET method using SoftSorbi-II ver.1.0. machine.

Thermal-conductivity of the autoclaved specimens was determined by the cylindrical probe method using ITP-MG4 Zond apparatus. Vapor permeability was measured according to the procedure described in the Russian Standard GOST 31359-2007 [18].

\section{Results}

The mix design of aerated autoclaved concrete was developed using design of experiment method considering the following parameters: slaked product content, water/solid ratio and content of $\beta$-hemihydrate calcium sulfate (\%). The aerated concrete with density of $800 \mathrm{~kg} / \mathrm{m}^{3}$ and compressive strength of 4.5 MPa was used as a reference.

In order to describe the binder system response by variation of the given parameters, adequate regression equations and yield surfaces were developed as depicted in Figure 1.
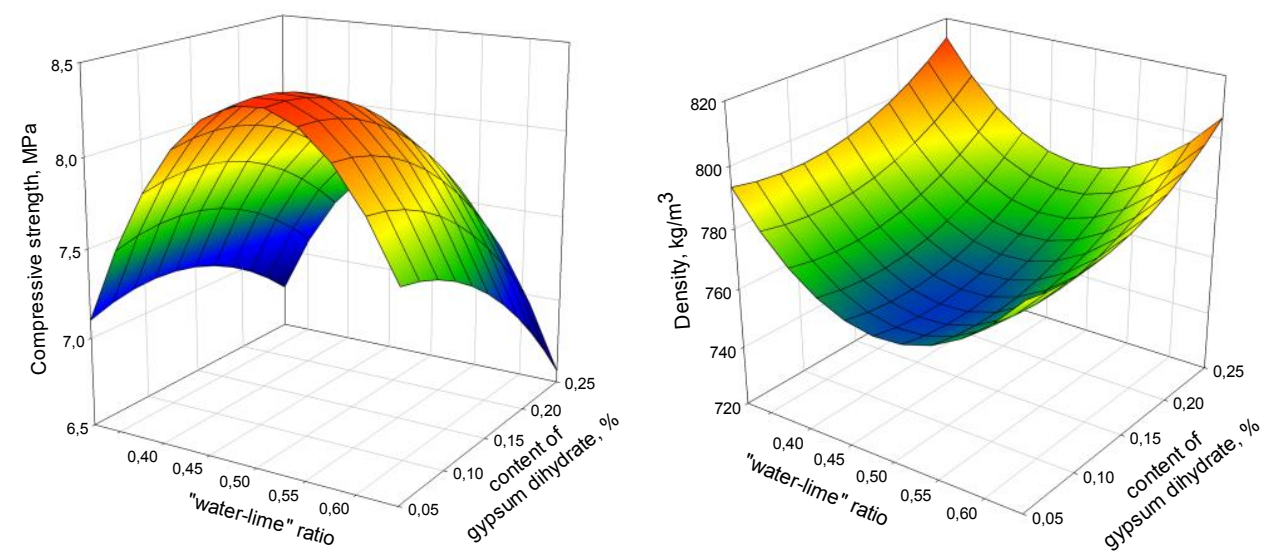

Fig. 1. The effect of water/solid ratio and content of $\beta$-hemihydrate calcium sulfate on density and compressive strength of aerated concrete.

Figure 1 demonstrated that the incorporation of previously slaked gypsum-lime binder into the aerated mixture enables to improve compressive strength performance and reduce density and water demand from 0.5 to 0.48 of the specimens.

The aerated concrete after autoclave treatment demonstrated the absence of $\mathrm{SO}_{4}^{2-}$ ions, confirming the reactivity of $\beta$-hemihydrate calcium sulfate during structure formation. Therefore, the optimal mix composition of aerated concrete contented $0.15 \%$ of $\beta$ hemihydrate calcium sulfate with 0.4 water/solid ratio, resulting in a significant increase of compressive strength from 4.5 to $8.5 \mathrm{MPa}$, and density reduction from 800 to $760 \mathrm{~kg} / \mathrm{m}^{3}$. 
Sulfate activation positively effected pore formation in concrete matrix. Structural skeleton of the optimal composition demonstrated porosity increase from 70 to $75 \%$ as well as homogeneous pore distribution (Figure $2 b$ ). Pores were spherical with $0.3-0.9 \mathrm{~mm}$ in diameter.
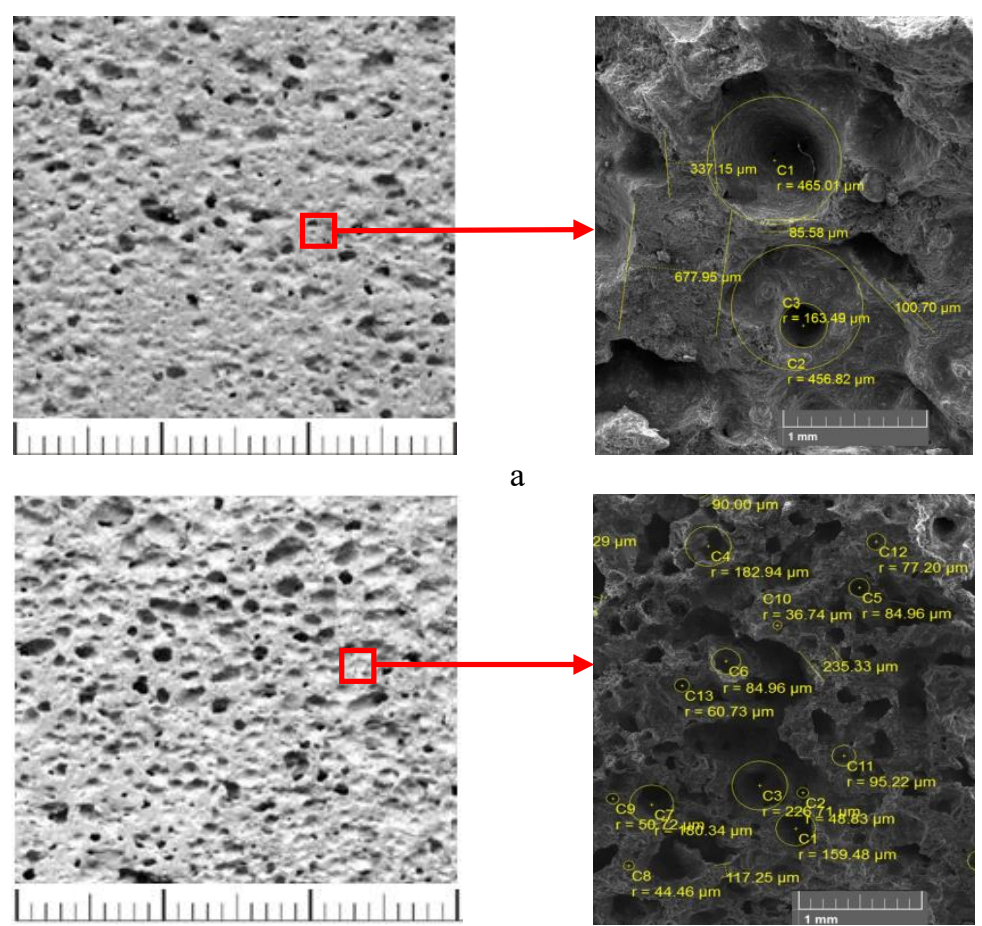

b

Fig. 2. SEM images of the aerated concrete after autoclave treatment: $a$ - composition $1 ; \mathrm{b}-$ composition 2 (Table 1).

According to the surface area BET data presented in Table 1, the volume of nanopores in concrete specimens was changed, where the volume of pores less than $94.6 \mathrm{~nm}$ was 0.007 $\mathrm{cm}^{3} / \mathrm{g}$ for reference specimen, and the volume of those for the experimental specimen was $0.018 \mathrm{~cm}^{3} / \mathrm{g}$. Formation of proper porous structure is the key parameter to improve thermal characteristics of concrete, because density reduction causes the decrease of thermal conductivity from 0.19 to $0.17 \mathrm{~W} /\left(\mathrm{m} \cdot \mathrm{C}^{\circ}\right.$ ) (Table 1$)$, improving thermal characteristics of aerated concrete.

Table 1. Characteristics of the aerated concrete after autoclave treatment.

\begin{tabular}{|c|c|c|c|c|c|c|c|c|}
\hline$\stackrel{\star}{\Sigma}$ & 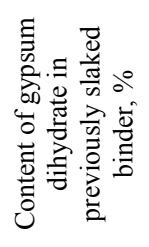 & 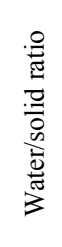 & 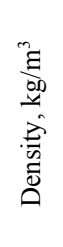 & 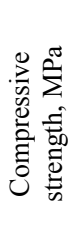 & 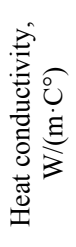 & 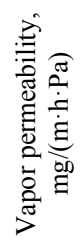 & 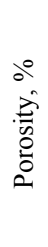 & 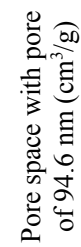 \\
\hline 1 & 0 & 0.50 & 800 & 4.5 & 0.19 & 0.14 & 70 & 0.007 \\
\hline
\end{tabular}




\begin{tabular}{|c|c|c|c|c|c|c|c|c|}
\hline 2 & 0.15 & 0.48 & 760 & 8.5 & 0.17 & 0.16 & 75 & 0.018 \\
\hline $\begin{array}{c}\text { According to } \\
\text { Russian } \\
\text { Standard } \\
31359-2007\end{array}$ & - & - & 800 & $2.5-7.5$ & 0.19 & $\begin{array}{c}0.14 \text { at } \\
\text { least }\end{array}$ & - & - \\
\hline
\end{tabular}

Mix 2 of the produced aerated concrete specimen meets the requirements of the Russian Standard GOST 31359-2007 [19] in terms of vapor permeability, which was $12 \%$ higher than that for reference mix 1 (Table 1). That means it can provide the "breathing wall" effect and keep in-door microclimate optimal.

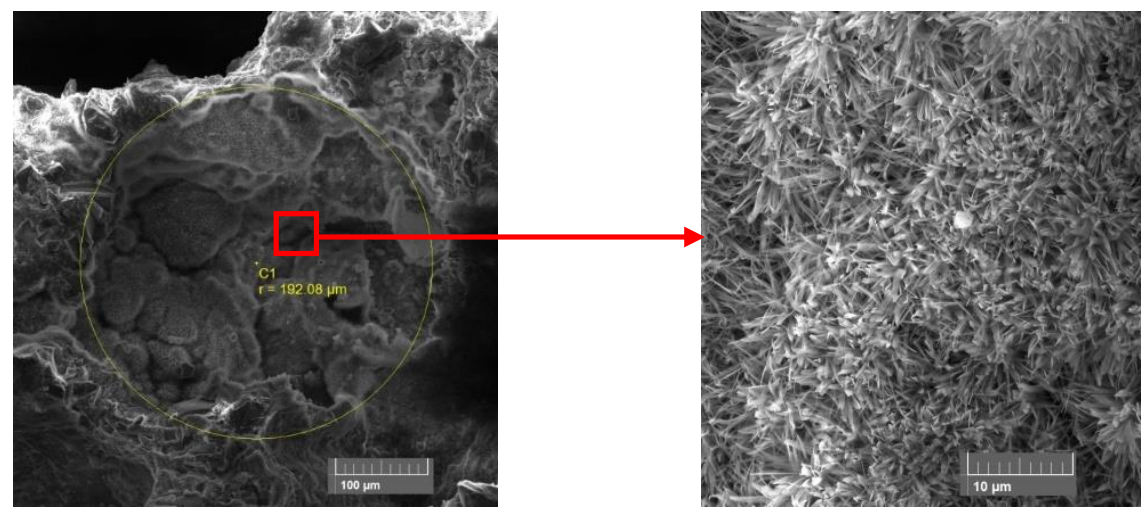

Fig. 3. SEM images of the mix 2 (Table 1).

Microstructure of an interporous zone as the most important zone in aerated concrete matrix responsible for with density and strength performance demonstrated the increase of structural packing density (Figure 3). Hydrothermal curing conditions are favorable for needle-like and stem-like crystal formations, which are typical for $11 \AA$-tobermorite that serves as a reinforcing element at micro level structure strengthening structure of aerated concrete.

\section{Conclusions}

This work demonstrated the opportunity to control thermal- and sound-insulating performance of aerated concrete due to homogeneous pore distribution, required density of interporous zone, required size and shape of particles. It can be achieved by controlling of hydration process in the binder system. Using method of lime sulfate activation allowed maximally intensify lime reactivity and stimulate the chemical interaction between components in the changing and rheological characteristics of fresh concrete mixture and mineral composition of aerated concrete. Increasing porosity, formation of multudispersed pores and their homogeneous distribution led to density reduction of the aerated concrete up to $5 \%$. The formation of needle-like crystals helps to reinforce matrix structure improving density of interporous zone, reduce structure imperfection and double the compressive strength of aerated concrete.

The developed aerated concrete is characterized by complex of improved thermal characteristics including heat conductivity reduction from 0.19 to $0.17 \mathrm{~W} /\left(\mathrm{m} \cdot{ }^{\circ} \mathrm{C}\right)$, vapor permeability increase from 0.14 to $0.16 \mathrm{mg} /(\mathrm{m} \cdot \mathrm{h} \cdot \mathrm{Pa})$ and that meets the requirements of modern standards of thermal insulation, energy saving and microclimate parameters. The application of developed concrete is good approach to produce environmentally friendly, 
sustainable and energy efficient structure at the stage of design, production and operation of high-rise buildings in today's megapolises.

\section{Acknowledgements}

The work is realized in the framework of the Program of flagship university development on the base of the Belgorod State Technological University named after V.G. Shoukhov, using equipment of High Technology Center at BSTU named after V.G. Shoukhov.

\section{References}

1. Yu.A. Matrosov, V.N., Yarmakovsky, Construction technologies, 6(40), 24-28 (2005).

2. S.G. Abramyan, T.A. Matviichuk, Engineering Journal of Don, 1 (44), 74 (2017).

3. Yu.A. Tabunshchikov, M.M. Brodach, ABOK: Ventilation, heating, air-conditioning, heat supply system and construction thermal physics, 1, 14-21 (2013).

4. V.S. Lesovik, Vestnik MGSU, Vol. 12, 1 (100), 9-16 (2017).

5. N. I. Vatin, A.S. Gorshkov, S. V. Kornienko, I. I. Pestryakov, Roofing and insulating materials, 2, 22-31 (2016).

6. R. Lesovik, Y. Degtev, M. Shakarna and Levchenko A. Modern Applied Science, 9 (1), 45-50 (2015).

7. A. E. Knyazev, Technologies of technosphere safety, 3 (55), 35 (2014).

8. A.S. Inozemtcev, E.V. Korolev, Smirnov V.A. Structural Concrete. T. 18, 1, 67-74 (2017).

9. V.S. Lesovik, M.Yu. Elistratkin, M.V. Absimetov, E.V. Kogut, Regional architecture and engineering, 3 (32), 11-20 (2017).

10. V.S. Lesovik, E.V. Fomina, O.V. Khotomchenko, Investigation of application conditions for construction materials taking into account a growth of environmental impact (Energy- and source-saving, environmentally-friendly chemical-engineering processes of environmental protection. Proceedings of International scientific and technical conference of BSTU named after V.G. Shoukhov, Belgorod, 2015) 409-414.

11. V.S. Lesovik, Belgorod: BSTU, pp: 287 (2016).

12. E.V. Fomina, N.P. Kudeyarova, Izvestia Vusov. Severo-Kavkazsky region. Technical sciences, 6, 17-19 (2006).

13. E.V. Fomina, N.I. Altynnik, V.V. Strokova, V.V. Nelubova, A.B. Bukhalo, Construction materials J., 9, 33-35 (2011).

14. E.V. Fomina, Bulletin of Belgorod State Technological University named after V.G. Shoukhov J., 4, 7-11 (2013).

15. Russian standard 25485-89 «Cellular concretes. Specifications».

16. Russian standard 30256-94 «Building materials and products. Method of thermal conductivity determination by cylindrical probe».

17. Russian standard 25898-83 «Building materials and products. Methods of steamtightness determination».

18. Russian standard 5382-91 «Cements and materials for cement production. Chemical analysis methods».

19. Russian standard 31359-2007 «Cellular autoclave curing concretes. Specifications». 